comfortable; pulse strong, and there had been intervals of from six to eight hours entire cessation from bleeding.

26th, 8 A.M.-Patient doing well, though he had some bleeding dur ing the night. A marked change in the consistency of the blood; coas gula forming. Enjoined strict quietude. On the afternoon of the same day, the brother of the patient called to inform me that the hemorrhage had entirely ceased. During the forenoon of the $27 \mathrm{th}$, called, and found him again much exhausted, having bled during the night. Was informed that on the previous afternoon, the hemorrhage being checked, he arose, made a change of clothing, and underwent no small amount of exertion. This day relinquished all charge of the case (by the sanction of the patient's employer, who first solicited my services), in consequence of other treatment being submitted to, which $I$ as well as his employer conceived to be wholly inconsistent, and with which I could have no sympathy.
4 Hamilton Place, April 26, 1854.
E. T. WiLson, M.D.

SELF-LIMITED DISEASES-IUR. CARPENTER TS. DR. CHURCHHLL.

[Communicated for the Boston Medicaland Surgica] Journtal.]

Dr. B. Carpenter, in his dissertation on "Selfslimited Diseases," says of hooping cough, "Do what you may, you cannot arrest its course." Now, without advancing any opinion of my own, and knowing, as I do, Dr. C. to be a most worthy man, and a good physician, and knowing. too, that doctors will sometimes disagree, $I$ wish to place by the side of Dr. C.'s statements, some of an opposite nature made by Dr. Fleetwood Churchill. In the Monthly Journal of Medical Science, August, 1853, and re-published in the 28th Part of Braithwaite's Retrospect, Dr. Churchill gives the following as his experience of the use of chloroform in hooping cough :-

"CASE I.-Miss D., æt. 16, had had hooping cough a month, when I prescribed chloroform. There was no complication, but the hooping was fiequent, especially during the night. She was directed to have the chloroform in readiness, and to use it with each paroxysm, and she as sures me that in two days the hoop ceased. The cough lasted a few days longer, but it was slight and not in kinks.

"C CASE II.-Miss A., æt. 20, had been ill with hooping cough for about three weeks, when I prescribed chloroform. The cough was not very frequent, and there was no complication. Two days sufficed with her also to relieve her of the hoop; and the slight cough which remained subsided after a week or ten days.

"In these two cases the effect seemed quite magical; both had the disease well marked, and the families of both were prepared for a disease of two or three months' duration, as was the case with their other children.

"CAse III.-Miss B., æt. 18, took the complaint from her brother, whorn I was attending, and I therefore had an opportunity of giving chloroform from the commencement. She did not hoop any time she coughed; but she was directed to use the chloroform whenever she felt 
the tickling in the larynx, without waiting for a cough. By doing so, she found that she could postpone the congh indefinitely, and if it came on suddenly, the use of the chloroform instantly suspended it. About three weeks elapsed before the tendency to congh and the use of chloroform ceased; but during that time she lost neither appetite nor flesh. She slept well, was in good spirits, and able to follow her usual occupation. She went to the country quite well."

Now, it is presumed both these excellent physicians think they are right; but, for one, I have learned that great men may be mistaken. I mean no disrespect to Dr. Carpenter by placing side by side, in your valuable Journal, such different statements; for there are few, if any, in the profession, for whom $I$ have a higher regard than for him.

Boston, April, 1854.

W. M. Connell.

\section{ALCOHOL AS A MEDICINE.}

[Communicated for the Boston Medica] and Surgical Journal.]

Mrssrs. Epitors,-I perceive that the subject of the medical use of alcohol is faily introduced into your valuable Journal. It is a subject of deep interest just now in the Pine Tree State, as being intimately connected with one of the grreat leading questions of moral reform. It is rare with us that a respectable man will advocate the use of intoxicating drinks as a beverage; but the mass believe, or affect to believe, that they are necessary for medicine. That such opinions are founded upon medical authority, no one can doubt. Physicians first introduced this poison into practice; and where substitutes can be found they should be the first to discard it, on account of the enormous moral and physical evils it has caused and is causing to suffering humanity. We have a law in Maine which effectually shuts up the grog shops, whenever and wherever it is enforced; but at the same time it leaves a door open wide enough at all times for any one to pass and gratify a depraved appetite, if he will only pronounce the talismanic words, "for medical purposes." One man for every five hundred inhabitants is licensed to sell liquors for medicine. It is rare that this man is a physician, and yet he is made sole judge of the necessity for such medicines, and thus every man becomes his own plyysician in the use of a most potent article. And why should he not, since physicians, from time inmemorial, have declared it an invaluable remedy, never to be dispensed with if it could be had, nay, that it should be kept as one of the household gods without which no family is safe.

The great question is, cannot there be substitutes for the domestic use of alcololics?" Dr. Gilman thinks "the whole community, including the medical faculty, need more light upon this subject." Dr. Hall thinks " as much light exists in regard to the use of alcohol, as is known in regard to many other useful and important remedial agents." When Dr. Hall will show any other "useful and imporant remedial agent" that has done a tithe of the evil to humanity, both morally and physically, that alcohol has done, then will I agree with him to enter into an exami- 